\title{
An epoxysterol and other constituents of Tanzania soft corals
}

\author{
A. SADRI SAID \\ Institute of Marine Sciences, P.O. Box 668, Zanzibar, Tanzania. \\ Corresponding author, E-mail: sadri@ims.udsm.ac.tz, Tel: +2552422 30741
}

\begin{abstract}
Three biologically active Lobophytum species, L. crassum von Marenzeller (1886), L. rotundum TixierDurivault (1957) and L. venustum Tixier-Durivault (1957) and one Sinularia species were phytochemically investigated. Lobophytum rotundum afforded an epoxysterol (1), cembraolide (2), and fatty acid ester (4), and ether glycerols (6 and 7). Compound $\mathbf{2}$ was also isolated in L. crassum together with another fatty acid ester (5). Lobophytum venustum produced epoxycembrene 3 and compound 4 . Two ether glycerols $(\mathbf{6}$ and 8 ) were isolated from the Sinularia species. This paper reports the isolation and structure elucidation of compounds $\mathbf{1}$, and 4-8.

(C) 2010 International Formulae Group. All rights reserved.
\end{abstract}

Keywords: Marine sterols, Cnidaria, soft corals.

\section{INTRODUCTION}

Recent decades have witnessed extensive exploration of world oceans as a new frontier for possible sources of drugs (Kijjoa and Sawangwong, 2004). This effort has led to isolation of a number of novel bioactive compounds, some of which are currently in the preclinical and clinical stages of drug development (Haefner, 2003). Each year an increasing number of novel bioactive marine natural products are reported in the literature (Blunt et al., 2009), indicating that marine environments will continue to be prolific source of bioactive compounds for many years to come. Phytochemical investigations on soft corals have afforded five major classes of marine natural products including cembranolides, sterols, sesquiterpenes, furanoids and fatty acid derivatives. A number of compounds falling under these classes have been found to possess potential biological activities including cytotoxicity and anti-inflamatory properties (Newman and Cragg, 2004). As part of our ongoing search for bioactive agents from marine organisms (Said, 2005), we examined extracts from three soft corals $L$. crassum, $L$. rotundum, $L$. venestum and an unidentified Sinularia species collected from Pange Reef, Zanzibar. This paper report on some compounds isolated from these organisms.

\section{MATERIALS AND METHODS}

\section{General method}

All solvents were redistilled. Merck silica gel 60 (230-400 mesh) was used for vacuum flash chromatography. Infra Red (IR) spectra were taken on Shimadzu IR-435 Spectrophotometer and Nuclear Magnetic Resonance (NMR) experiments were 
conducted in $\mathrm{CDCl}_{3}$ with a Bruker $\mathrm{AM} 400$ instrument. Signals are reported in parts per million $(\delta)$, referenced to the solvent used. High Resolution Mass Spectra (HRMS) were measured on a Varian VG 7070E instrument at $70 \mathrm{eV}$. Ultra Violet (UV) spectra were run on a Shimadzu UV-240 spectrophotometer. GC/MS was carried out on a DANI 3800 GC machine coupled to a VG 7070E double focusing mass spectrometer. A fused silica capillary column (Sil-5B WCOT, Chrompack) with diameter $0.32 / 0.45$ (internal/external) and $25 \mathrm{~m}$ long was used with helium as the carrier gas. Samples were injected at $250{ }^{\circ} \mathrm{C}$, the oven temperature being programmed at the rate of $10{ }^{\circ} \mathrm{C} / \mathrm{min}$ (from 150 to $300{ }^{\circ} \mathrm{C}$ ).

\section{Biological materials, collection and identification}

All four coral species were collected from Pange Reef in Zanzibar $\left(06^{\circ} 11.659^{\prime} \mathrm{S}\right.$; $\left.039^{\circ} 07.819^{\prime} \mathrm{E}\right)$ on 15 April 1992. The corals were identified by Dr. L.P. van Ofwegen of the National Natuurhistorisch Museum (RMNH), Leiden, Netherlands and Prof. Y. Beneyahu of the Department of Zoology, Tel Aviv University, Israel (Beneyahu and van Ofwegen 1992). Voucher specimens are preserved at RMNH and at the Zoological Museum of Tel Aviv University (ZMTAU) with voucher numbers L. crassum (RMNH Coel. 181917, ZMTAU Co 26276), L. rotundum (RMNH Coel. 18922) and $L$. venestum (RMNH Coel. 18925)

\section{Extraction and isolation}

Freeze dried soft corals were soaked separately and consecutively in methanol, followed by a mixture of methanol/dichloromethane (1:1) for 48 hours in each solvent. Extracts from each species were combined and partitioned between water and organic solvents to give $\mathrm{C}_{6} \mathrm{H}_{14}, \mathrm{CH}_{2} \mathrm{Cl}_{2}$, n$\mathrm{BuOH}$ and water fractions. The $\mathrm{CH}_{2} \mathrm{Cl}_{2}$ solubles from each soft coral species exhibited cytotoxicity against brine shrimp larvae and were thus subjected to vacuum liquid chromatography (VLC), eluting with hexane containing increasing amounts of ethyl acetate. The first four fractions of each extract were composed of long chain fatty acids esters. The fifth fraction of $L$. rotundum extract contained the epoxysterol (1). The cembranolide (2) was obtained from the fifth fraction of $L$. crassum and $L$. rotundum extracts. The fifth fraction of $L$. venestum contained the epoxycembrenoid (3). The six and the seventh fractions of each extract were found to contain mixtures of sterols while the ether glycerols were obtained from the most polar fractions.

\section{Epoxysterol (1)}

Repeated column chromatography of the fifth fraction of L. rotundum on silica gel eluting with $20 \%$ EtOAc/Pet ether produced crude $\mathbf{1}$ as a white gum, which was purified further by gel chromatography using sephadex LH-20 eluting with $\mathrm{MeOH}$. Recrystallization from a mixture of n-hexane and EtOAc (3:1, $\mathrm{v} / \mathrm{v})$ yielded white crystals $(18 \mathrm{mg}, 0.02 \%$ based on weight of dried material), m.p. 228$230{ }^{\circ} \mathrm{C},[\alpha]_{\mathrm{D}}=-0.16^{\circ}\left(\mathrm{c}=0.14, \mathrm{CHCl}_{3}\right), \mathrm{IR}, v$ $\left(\mathrm{CHCl}_{3}\right), 2892,2721,1720,1460,984$ and $760 \mathrm{~cm}^{-1} .{ }^{1} \mathrm{H}-\mathrm{NMR}\left(\mathrm{CDCl}_{3}\right) \delta 0.678(\mathrm{~s}, 3 \mathrm{H})$, $1.18(\mathrm{~s}, 3 \mathrm{H}), 0.876(\mathrm{~d}, J=6.47 \mathrm{~Hz}, 3 \mathrm{H}), 0.90$ (m, 2H), 0.917(d, $J=6.47 \mathrm{~Hz}, 3 \mathrm{H}), 1.05-2.00$ (m, 19H) 1.39 (s, 3H), 1.97 (s, 3H), 2.09 (dd, J $=11.4,12 \mathrm{~Hz}, 1 \mathrm{H}), 3.54$ (t $J=3 \mathrm{~Hz}, 1 \mathrm{H}), 4.10$ $(\mathrm{m}, 1 \mathrm{H}) .{ }^{13} \mathrm{C}-\mathrm{NMR}\left(\mathrm{CDCl}_{3}\right) \delta 36.20(\mathrm{C}-1)$, 28.11 (C-2), 76.07 (C-3), 34.52 (C-4), 41.92 (C-5), 30.20 (C-6), 32.37 (C-7),34.65 (C-8), 55.92 (C-9), 38.27 (C-10), 21.17 (C-11), 30.84 (C-12), 42.73 (C-13), 45.86 (C-14), 27.73 (C-15), 18.93 (C-16), 40.73 (C-17), 14.48 (t, C-18), 12.16 (t, C-19), 85.96 (C-20), 16.87 (C-21), 67.67 (C-22), 24.12 (C-23), 39.91 (C-24), 23.32 (C-25), 22.90 (C-26), $170.47 \quad(\mathrm{C}=\mathrm{O}), \quad 22.55 \quad\left(\mathrm{CH}_{3}\right.$-acetoxy $)$. HREIMS $m / z \quad 432.3508\left[^{[M}\right]^{+}$(Calcd. for $\mathrm{C}_{28} \mathrm{H}_{48} \mathrm{O}_{3} 432.3514$ ). 
1-O-octadecyl-sn-glycerol (6) and 1-Ooctadecyl-2,3-O-dihexadecanoyl-sn-gylcerol (7)

Vacuum liquid chromatography of the $\mathrm{CH}_{2} \mathrm{Cl}_{2}$ extract of L. rotundum gave the two most polar fractions which contained two major compounds 6 and 7 together with a reddish oily material, hence, were combined. Repeated column chromatography of the combined fraction ultimately removed the reddish material and afforded separation of the two compounds. These compounds were further purified by recrystallization from ethyl acetate. Yield (6: $15 \mathrm{mg}, 0.016 \%$ and 7: 20 mg $0.02 \%$ based on the weight of the dried material).

\section{1-O-octadecyl-sn-glycerol (6)}

IR $\vee\left(\mathrm{CHCl}_{3}\right), 3450,2923,1461,1231$, 1205 and $1110 \mathrm{~cm}^{-1} .{ }^{1} \mathrm{H}-\mathrm{NMR}, \delta 0.88(\mathrm{t}, J=$ $6.78 \mathrm{~Hz}, 3 \mathrm{H}), 1.25$ (br s, 30H), 1.60 (m), 2.20 (br s, OH), 2.73 (br s, OH), 3.45 (td, $J=6.58$, $2.79 \mathrm{~Hz}, 2 \mathrm{H}$ ), 3.50 (ddd, $J=6.69,4.07 \& 6.09$ $\mathrm{Hz}, 2 \mathrm{H}$ ), 3.70 (ddd, $J=11.38,3.82$ and 5.17 $\mathrm{Hz}, 2 \mathrm{H}), 3.85$ (m, 1H, carbinol H). ${ }^{13} \mathrm{C}-\mathrm{NMR}$, $\delta, 14.10(\mathrm{q}), 22.67(\mathrm{t}), 29.34(\mathrm{t}), 29.66(\mathrm{t})$, $31.90(\mathrm{t}), 64.29(\mathrm{t}), 70.39(\mathrm{~d}), 71.84(\mathrm{t}), 72.56$ (t). LREIMS $\mathrm{m} / \mathrm{z}\left(\%\right.$, rel. int.) $345\left([\mathrm{M}+1]^{+}\right.$, 5), , 326 (1), 313 (3), 283 (14), 255 (1), 253 (13), 169 (2), 155 (3), 57 (100), 43 (71).

\section{1-O-octadecyl-2,3-O-dihexadecanoyl-sn- gylcerol (7)}

IR, $v\left(\mathrm{CHCl}_{3}\right) 2923,1727,1426,1230$, and $1113 \mathrm{~cm}^{-1} .{ }^{1} \mathrm{H}-\mathrm{NMR}, \delta 0.88(\mathrm{t}, J=6.49$ $\mathrm{Hz}, 9 \mathrm{H}), 1.25$ (br s, 76H), 1.40-1.55 (m, 6H), $2.30(\mathrm{~m}, 4 \mathrm{H}), 3.40(\mathrm{~m}, 4 \mathrm{H}), 4.16\left(\mathrm{H}_{\mathrm{A}}\right), 4.34$ $\left(\mathrm{H}_{\mathrm{B}}\right)$, and $5.20\left(\mathrm{H}_{\mathrm{X}}\right)\left(\mathrm{ABX}, J_{\mathrm{AB}} 11.91 \mathrm{~Hz}, J_{\mathrm{AX}}\right.$ $\left.=6.46 \mathrm{~Hz}, J_{\mathrm{BX}}=3.69 \mathrm{~Hz}\right) .{ }^{13} \mathrm{C}-\mathrm{NMR}, \delta, 14.10$ $(\mathrm{q}), 2.69(\mathrm{t}), 24.57(\mathrm{t}), 27.20(\mathrm{t}), 29.33(\mathrm{t})$, $29.50(\mathrm{t}), 29.69(\mathrm{t}), 31.92(\mathrm{t}), 31.99(\mathrm{t}), 34.15$ $(\mathrm{t}), 62.72(\mathrm{t}), 68.94(\mathrm{t}), 70.06(\mathrm{~d}), 71.75(\mathrm{t})$, 173.13 (s), 173.44 (s). LREIMS, $m / z$ (\%, rel. int.) $565\left(\left[\mathrm{M}^{+}\right.\right.$- 255], 1) 537 (2), 382 (3), 313 (13), 281 (2), 255 (2), 225 (10), 69 (50), 57 (92), 28 (100)

\section{1-O-octadecyl-3-O-hexadecanoyl-sn- glycerol (8)}

Elution of VLC column of $\mathrm{CH}_{2} \mathrm{Cl}_{2}$ extract of an unidentified Sinularia species using $50 \%$ ethyl acetate in n-hexane gave the most polar fraction containing one major compound. Repeated column chromatography of this fraction gave compound $\mathbf{8}$, which was purified by gel chromatography using sephadex LH-20 eluting with methanol, followed by recrystallization from ethyl acetate to yield white crystals $(333 \mathrm{mg}, 0.17 \%$ based on the weight of dried material), m.p. 86-87 ${ }^{\circ} \mathrm{C}$. IR, v $\left(\mathrm{CHCl}_{3}\right), 3450,2923,1727$, 1462, 1250, 1170, $1113 \mathrm{~cm}^{-1}$. ${ }^{1} \mathrm{H}-\mathrm{NMR}, \delta$, $0.88(\mathrm{t}, J=6.49 \mathrm{~Hz}, 6 \mathrm{H}), 1.25(\mathrm{br} \mathrm{s}, 54 \mathrm{H})$, $1.60(\mathrm{~m}), 2.30(\mathrm{t}, J=7.50 \mathrm{~Hz}, 2 \mathrm{H}), 2.51(\mathrm{~d}, J$ $=4.55 \mathrm{~Hz}, \mathrm{OH}), 3.46(\mathrm{~m}, 4 \mathrm{H}), 4.01(\mathrm{~m}, 1 \mathrm{H})$, $4.16(\mathrm{~m}, 2 \mathrm{H}),{ }^{13} \mathrm{C}-\mathrm{NMR}, \delta, 14.10(\mathrm{q}), 22.68$ $(\mathrm{t}), 24.93(\mathrm{t}), 26.07(\mathrm{t}), 29.13(\mathrm{t}), 29.46(\mathrm{t})$, $29.67(\mathrm{t}), 34.17(\mathrm{t}), 65.40(\mathrm{t}), 68.87(\mathrm{~d}), 71.39$ (t), $71.76(\mathrm{t}), 173.95(\mathrm{~s})$. LREIMS $\mathrm{m} / \mathrm{z}$ (\%, rel. int.), $583\left([\mathrm{M}+1]^{+}, 3\right), 565$ (3), 537 (1), 327 (8), 313 (15), 239 (62), 57 (100) 55 (42), 29 (13).

\section{RESULTS AND DISCUSSION}

$3 \beta$-acetoxy-20,22-epoxy-24-norcholestane (1)

This compound was obtained as white powder. The MS showed the molecular ion peak at $m / z$ 432, from which, together with ${ }^{1} \mathrm{H}$ and ${ }^{13} \mathrm{C}$-NMR spectra, formula $\mathrm{C}_{28} \mathrm{H}_{48} \mathrm{O}_{3}$ was deduced. The IR spectrum showed a strong absorption at $1720 \mathrm{~cm}^{-1}$ due to an acetyl carbonyl carbon which was confirmed by the presence of a signal at $\delta 170.49$ in the ${ }^{13} \mathrm{C}$ NMR and a signal at $\delta 1.97$ (s. $3 \mathrm{H}$ ) in the ${ }^{1} \mathrm{H}$ NMR spectrum. Both $1 \mathrm{H}-$ and 13C-NMR spectra showed the compound to be a sterol. Thus in addition to the acetyl carbon signal the 13C-NMR spectrum consisted of all resonances for a C-3 oxygenated C26 sterol (Blunt and Stothers, 1977). The ${ }^{1} \mathrm{H}-\mathrm{NMR}$ spectrum exhibited peaks at $\delta 0.678(\mathrm{~s}, 3 \mathrm{H})$ 
and $1.18(\mathrm{~s}, 3 \mathrm{H})$ which are characteristic of $\mathrm{C}$ 19 and C-18 quaternary methyl groups in sterols (Zurcher, 1963). Two doublets at $\delta$ 0.876 and 0.917 (both $J=6.47 \mathrm{~Hz}$, each $3 \mathrm{H}$ ) and one singlet at $\delta 1.39(3 \mathrm{H})$ indicated that the sterol side chain is trimethylated, and hence the compound consists of a 24norcholestane skeleton (Kerr and Baker, 1991; Sarma et al., 2005). Apart from a signal at $\delta 170.49$, the ${ }^{13} \mathrm{C}$-NMR spectrum exhibited peaks due to a quaternary $\mathrm{C}-\mathrm{O}$ carbon at $\delta$ 85.95 and two secondary C-O carbons at $\delta$ 76.06 and 67.63. The signal at $\delta 76.06$ is at a typical chemical shift for C-3- acetylated sterols (Kobayashi et al., 1983). This corresponds to a carbinol methine proton resonance at $\delta 4.10(\mathrm{~m}, 1 \mathrm{H})$ in the ${ }^{1} \mathrm{H}-\mathrm{NMR}$ spectrum. The ${ }^{1} \mathrm{H}-\mathrm{NMR}$ spectrum also exhibited another carbinol methine proton at $\delta$ 3.54 (t, $J$ ca. $3 \mathrm{~Hz}, 1 \mathrm{H})$. The MS and other spectral data showed the compound to consist of three oxygen atoms, two of which being associated to a C-3 acetoxy group. The third oxygen in the molecule, in accordance with the above spectral data, must be subsitituted on the side chain and it has to be bonded to two carbon atoms, forming either an oxetane or an epoxide ring. However, considering the splitting pattern of the methine proton at $\delta$ 3.54 and the cross peaks in the COSY spectrum of $\mathbf{1}$, an oxetane ring is ruled out. The epoxide ring can be placed between $\mathrm{C}-20$ and $\mathrm{C}-22, \mathrm{C}-22$ and $\mathrm{C}-23$ or $\mathrm{C}-23$ and $\mathrm{C}-24$ in the molecule. The possibility of the epoxide moiety being bonded between C-23 and C-24 was also ruled out since this requires two methyl group resonances at $c a . \delta 1.4$, instead of only one which is found in the spectrum of 1. Assignment of the epoxide ring between $\mathrm{C}$ 22 and $\mathrm{C}-23$ is unfit because this would require three secondary $\mathrm{C}-\mathrm{O}$ absorptions in the $1 \mathrm{H}-$ and 13C-NMR spectra and three secondary methyl doublets in the ${ }^{1} \mathrm{H}-\mathrm{NMR}$ spectrum. Thus the epoxide ring is bonded between $\mathrm{C}-20$ and $\mathrm{C}-22$. Hence the singlet at $\delta$ 1.39 , which is particularly, dishielded, was assigned to $\mathrm{C}-21$ protons, and the doublets at $\delta 0.876$ and 0.917 were attributed to the secondary methyl protons at C-25 and C-26 (Kobayashi et al., 1983). The quaternary C-O carbon which resonates at $\delta 85.95$ is thus due to $\mathrm{C}-20$, and the peak due to a secondary $\mathrm{C}-\mathrm{O}$ carbon at $\delta 67.63$ was assigned to $\mathrm{C}-22$. Correspondingly, the signal at $\delta 3.54$ in the ${ }^{1} \mathrm{H}-\mathrm{NMR}$ was attributed to a C-22 methine proton. The ${ }^{1} \mathrm{H}-\mathrm{NMR}$ signal at $\delta 2.09(\mathrm{dd}, J=$ 11.4 and $12.0 \mathrm{~Hz}$ ) was assigned to $\mathrm{C}-4$ protons in the molecule. The absence of any absorption between $\delta 4.90$ and 5.30 in the IHNMR and a signal between $\delta 120$ and 150 in the ${ }^{13} \mathrm{C}$-NMR suggested that there is no unsaturation in $\mathbf{1}$. The stereochemistry at position 3 was established on the basis of a homonuclear COSY spectrum that showed vicinal couplings between $\mathrm{H}-3(\delta 4.10)$ and $\mathrm{H}-$ 4axial ( $\delta 2.09$, dd, $J=11.4$ and $12.0 \mathrm{~Hz}$ ), this coupling constant suggesting a $\beta_{\text {equitorial }}$ configuration for the C-3 acetoxy group. The proposed structure was also confirmed by HMBC correlation of compound 1 (Figure 1).

\section{Mixtures of sterols}

This was isolated as white gums that appeared as homogeneous single spots on TLC. The ${ }^{1} \mathrm{H}$-NMR spectrum of each of the gums exhibited signals which were comparable with ${ }^{1} \mathrm{H}-\mathrm{NMR}$ chemical shifts of known sterols (Sarma et al., 2005), Thus the spectra exhibited absoptions at $\delta-0.13(\mathrm{dd}, J$ $=4$ and $6 \mathrm{~Hz}), 0.06-0.44(\mathrm{~m})$ and $0.45(\mathrm{dd}, J=$ 4.8 and $9 \mathrm{~Hz}$ ) which fitted well with reported ${ }^{1} \mathrm{H}-\mathrm{NMR}$ spectral values for sterols which bear a cyclopropyl ring in the side chain (Kerr and Baker, 1991). In addition to these signals the ${ }^{1} \mathrm{H}-\mathrm{NMR}$ spectra of the three gums also revealed absorptions at $\delta 3.53(\mathrm{~m})$ and 5.35 (m) with highest intensities, these being due to the $3 \alpha$-hydroxymethine and H-6 of the sterols in the mixtures (Zurcher, 1963). Correspondingly, the ${ }^{13} \mathrm{C}-\mathrm{NMR}$ spectra of the gums gave peaks at $\delta 71.75$ and 140.74 which 
were attributed to $\mathrm{C}-3$ and $\mathrm{C}-5$ in sterols (Kobayashi et al., 1983). The ${ }^{1} \mathrm{H}-\mathrm{NMR}$ spectra of the gums also exhibited weak signals at $c a$. $5.2(\mathrm{dd}, J=8.1$ and $16.0 \mathrm{~Hz}$ ) which suggested the presence of sterols which have olefinic character in the side chain (Kerr and Baker, 1991). This was corroborated by the presence of absorptions at $\delta 121.7$ and 122.1 in the ${ }^{13} \mathrm{C}$ NMR spectra of the gums. In addition to these signals, the ${ }^{\mathrm{I}} \mathrm{H}-\mathrm{NMR}$ spectrum of the gum from $L$. crassum also consisted of absorptions at $\delta 1.56(\mathrm{~s})$ and $4.66(\mathrm{~s})$ which indicated the presence of a trisubstituted double bond bearing a methyl group in a sterol side chain, and a terminal methylene group (Hat et al., 1985). The presence of a terminal methylene group in the sterols was supported by the signal at $\delta 109.31$ in the ${ }^{13} \mathrm{C}-\mathrm{NMR}$ spectrum of the gum, which appeared as a triplet. The mass spectra of all the substances from the three soft corals consisted of peaks at $\mathrm{m} / \mathrm{z}$ 299301, 271-273, 255-257, 231 and 213 which are characteristic peaks of the common sterols which have an unsaturated side chain (Kerr and Baker, 1991). Therefore in accordance with the ${ }^{1} \mathrm{H}$ - and ${ }^{13} \mathrm{C}$-NMR and mass spectral data discussed above, the gums from the three soft corals consist of sterols which have various modifications on the side chain. GCMS analysis indicated that each of the substances was a mixture of at least six sterols (Table 1) (Kerr and Baker, 1991; Sarma et al., 2005).

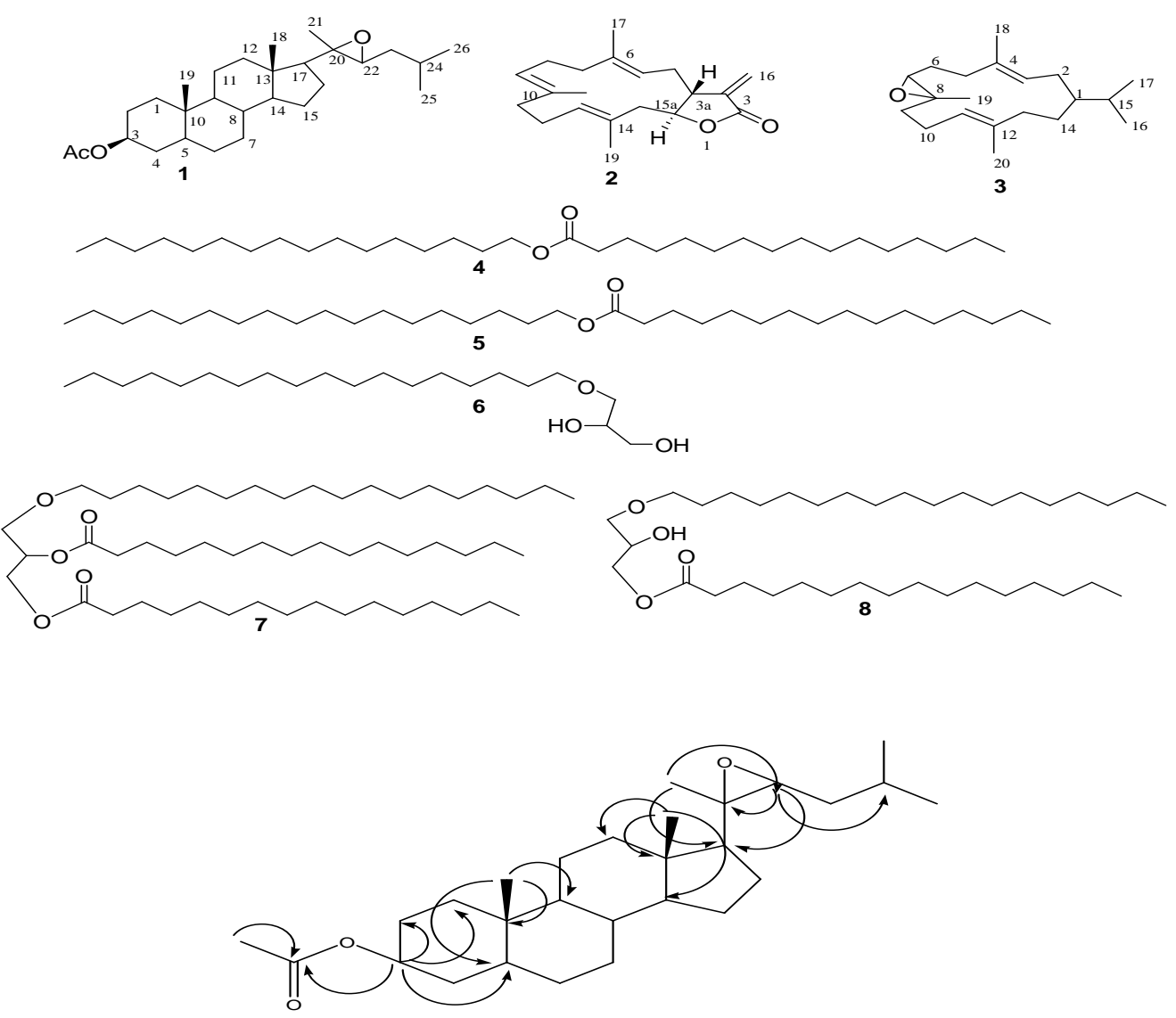

Figure 1: HMBC correlation of epoxysterol (1). 
Table 1: Composition of sterol mixtures from Lobphytum species (GC/MS).

\begin{tabular}{|c|c|c|c|c|}
\hline \multirow[t]{2}{*}{$\mathbf{R R T}^{\mathbf{a}, \mathbf{b}}$} & \multirow[t]{2}{*}{ Sterol } & \multicolumn{3}{|c|}{ Composition } \\
\hline & & L. crassum & L. rotundum & L. venestum \\
\hline 1.000 & Cholesterol & + & + & + \\
\hline 1.025 & 24-methylcholesta-5,25-dien-3 $\beta$-ol & + & + & + \\
\hline 1.053 & 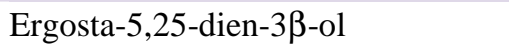 & + & - & - \\
\hline 1.053 & Ergosta-5,24(28)-dien-3 $\beta$-ol & + & + & + \\
\hline 1.065 & Ergosterol & + & + & + \\
\hline 1.066 & Unidentified & + & + & - \\
\hline 1.106 & Unidentified & + & + & - \\
\hline 1.113 & Demethylgorgosterol & + & - & + \\
\hline 1.113 & Demethylgorgostanol & + & + & - \\
\hline 1.197 & Gorgosterol & + & + & + \\
\hline 1.197 & Gorgostanol & + & - & - \\
\hline
\end{tabular}

${ }^{\mathrm{a}} \mathrm{RRT}=$ Retention time relative to cholesterol peak, ${ }^{\mathrm{b}}$ Average RRT for the three soft corals, $+=$ present, $-=$ absent

Hexadecylhexadecanoate octadecylhexadecanoate (5)

(4) and

Compound 4 was obtained as white powder. The IR spectrum of 4 showed absorptions at 1720 and $1247 \mathrm{~cm}^{-1}$. Since the spectrum did not reveal absorption due to a hydroxyl group the $\mathrm{C}-\mathrm{O}$ vibration at $1247 \mathrm{~cm}^{-}$ ${ }^{1}$ was assigned to an ester $\mathrm{C}-\mathrm{O}$ linkage, and therefore the absorption at $1720 \mathrm{~cm}^{-1}$ was attributed to an ester carbonyl. This assignment was confirmed by both the ${ }^{1} \mathrm{H}$ and ${ }^{13} \mathrm{C}$-NMR spectra. Thus the ${ }^{1} \mathrm{H}-\mathrm{NMR}$ spectrum consisted of signals at $\delta 2.30(\mathrm{t}, J=$ $7.0 \mathrm{~Hz}$ ) and $1.60(\mathrm{~m})$ due to $\mathrm{CH}_{2}$ groups $\alpha$ and $\beta$ to a carbonyl group and at $\delta 4.10(\mathrm{t}, J=6.7$ $\mathrm{Hz}$ ) due to a $\mathrm{CH}_{2}$ group linked to an oxygen atom. Similarly the ${ }^{13} \mathrm{C}-\mathrm{NMR}$ spectrum exhibited a carbonyl absorption at $\delta 173.9$ and a $\mathrm{CH}_{2}-\mathrm{O}$ signal at $\delta 64.3$, as expected for an ester functionality. Other ${ }^{1} \mathrm{H}-\mathrm{NMR}$ resonances indicated the presence of two methyl groups at $\delta 0.88(\mathrm{t}, J=6.9 \mathrm{~Hz})$ and 25 methylenes at $\delta$ 1.25 (br s). Both the $1 \mathrm{H}$-and ${ }^{13} \mathrm{C}-\mathrm{NMR}$ spectra did not reveal the presence of unsaturated carbons in the molecule. The MS of the compound showed the molecular ion at $\mathrm{m} / \mathrm{z}$ 480 which corresponds to the formula
$\mathrm{C}_{32} \mathrm{H}_{68} \mathrm{O}_{2}$. Other significant peaks appeared at $m / z \quad 257 \quad\left\{\left[\mathrm{CH}_{3}\left(\mathrm{CH}_{2}\right)_{14} \mathrm{COOH}_{2}\right]^{+}\right\}, \quad 224$ $\left\{\left[\mathrm{C}_{16} \mathrm{H}_{32}\right]^{+}\right\}, 57\left\{\left[\mathrm{C}_{4} \mathrm{H}_{9}\right]^{+}\right\}$and $43\left\{\left[\mathrm{C}_{3} \mathrm{H}_{7}\right]^{+}\right\}$. This fragmentation pattern fits well with structure $\mathbf{4}$ for the ester.

\section{Octadecyl hexadecanoate (5)}

This compound was also obtained as white powder. Its spectral features were the same as those observed for the hexadecyl ester 4 except that in the ${ }^{1} \mathrm{H}-\mathrm{NMR}$ spectrum of $\mathbf{5}$, the signal at $\delta 1.25$ represented 54 instead of 50 protons shown by the same signal in the spectrum of 4 . Furthermore, the MS of 5 exhibited the molecular ion at $\mathrm{m} / \mathrm{z} 508$, which is 28 mass units more than the $\mathrm{M}^{+}$peak for $\mathbf{4}$. This, in addition to the presence of only one carbonyl in the ${ }^{13} \mathrm{C}-\mathrm{NMR}$ spectrum of both 4 and $\mathbf{5}$, indicated that compound $\mathbf{5}$ has two additional $\mathrm{CH}_{2}$ groups than in $\mathbf{4}$. The MS of $\mathbf{5}$, like that of $\mathbf{4}$, exhibited a peak at $\mathrm{m} / \mathrm{z} 257$, which indicated the presence of a hexadecanoyl group in $\mathbf{5}$, as in $\mathbf{4}$. Therefore the two additional $\mathrm{CH}_{2}$ groups in $\mathbf{5}$ must be on the alcohol moiety. Hence compound $\mathbf{5}$ is octadecyl hexadecanoate. 


\section{1-O-octadecyl-sn-glycerol (6)}

Compound 6 was obtained as white powder. The IR spectrum of compound $\mathbf{6}$ showed a broad hydroxyl absorption at 3450 cm-l. The ${ }^{1} \mathrm{H}-\mathrm{NMR}$ spectrum of 6 exhibited broad peaks at $\delta 2.20(\mathrm{~s}, \mathrm{OH})$ and $2.73(\mathrm{~s}$, $\mathrm{OH})$ which were due to two free hyhroxyl groups. Absorptions at $\delta 1.60(\mathrm{~m}, 2 \mathrm{H})$ and 1.25 (br s, 30H) were attributed to a methylene group which is $\beta$ to an ether oxygen group and other fifteen methylene groups in the octadecyl chain respectively. The signal at $\delta 0.88(\mathrm{t}, J=6.78 \mathrm{~Hz}, 3 \mathrm{H})$ was assigned to a terminal $\mathrm{CH}_{3}$ group in the molecule. Furthermore the ${ }^{1} \mathrm{H}-\mathrm{NMR}$ spectrum of 6 exhibited the presence of three different types of $\mathrm{CH}_{2}-\mathrm{O}$ groups, two of which appeared as ABX systems and being adjacent to a carbinol carbon (Kingston et al., 1975). These signals appeared at $\delta 3.50\left(\mathrm{ABX}, J_{\mathrm{AB}}=\right.$ $\left.6.69 \mathrm{~Hz}, J_{\mathrm{AX}}=4.07 \mathrm{~Hz}, J_{\mathrm{BX}}=6.09 \mathrm{~Hz}, 2 \mathrm{H}\right)$ which was due to a methylene group $\alpha$ to both a carbinol and an ether oxygen, and at $\delta 3.70$ $\left(\mathrm{ABX}, J_{\mathrm{AB}}=11.38 \mathrm{~Hz}, J_{\mathrm{AX}}=3.82 \mathrm{~Hz}, \mathrm{~J}_{\mathrm{BX}}=\right.$ $5.17 \mathrm{~Hz}, 2 \mathrm{H}$ ) which was attributed to a methylene group $\alpha$ to a carbinol carbon only. The last $\mathrm{CH}_{2}-\mathrm{O}$ system was observed at $\delta 3.45$ $(\mathrm{td}, J=6.85,2.97 \mathrm{~Hz}, 2 \mathrm{H})$ and this was assigned to an octadecyl methylene group which is $\alpha$ to an ether oxygen. The carbinol proton appeared as a multiplet at $\delta 3.85$. The COSY spectrum of $\mathbf{6}$ confirmed the neighbourhood of the methylene groups and the CH-O group. The ${ }^{13} \mathrm{C}-\mathrm{NMR}$ spectrum of $\mathbf{6}$ gave absorptions for the three $\mathrm{CH}_{2}-\mathrm{O}$ carbons at $\delta 64.29,71.84$ and 72.50 . The spectrum also revealed the presence of a $\mathrm{CH}-\mathrm{O}$ group at $\delta$ 70.39. The rest of the ${ }^{13} \mathrm{C}-\mathrm{NMR}$ spectral data are in agreement with the proposed structure. The EIMS spectrum of compound 6 showed the expected $[\mathrm{M}+1]^{+}$peak at $m / z, 345$ which corresponds to the formula $\mathrm{C}_{31} \mathrm{H}_{54} \mathrm{O}_{3}$. The $\mathrm{M}^{+}$fragment cleaves 31 mass units to give a fragment ion at $m / z 313$ as expected for 1-O-alkyl-sn-glycerols (Mangold, 1983). The signal at $m / z, 326$ in the spectrum is due to the loss of a molecule of water from the molecular ion.

\section{1-O-octadecyl-3- $O$-hexadecanoyl-sn- glycerol (8)}

Compound $\mathbf{8}$ was obtained as white powder. The IR spectrum of $\mathbf{8}$ gave a band at $3450 \mathrm{~cm}^{-1}$ which was due to a hydroxyl group. Other significant absorptions in the spectrum appeared at 1727 and $1250 \mathrm{~cm}^{-1}$. As for 6 the ${ }^{1} \mathrm{H}-\mathrm{NMR}$ spectrum showed a glycerol oxygenation pattern in the molecule (Costantino et al., 1993). Thus the spectrum exhibited a peak at $\delta 2.51(\mathrm{~d}, J=4.55 \mathrm{~Hz}$, $\mathrm{OH}$ ) which was attributed to a hydroxyl group split by a carbinol hydrogen. A signal which appeared at $\delta 0.88(\mathrm{t}, J=6.49 \mathrm{~Hz}, 6 \mathrm{H})$ was due to two terminal methyl groups. A methylene group which is $\beta$ to carbonyl group appeared at $\delta 1.60(\mathrm{~m}, 2 \mathrm{H})$ and 27 other methylene groups resonated at $\delta 1.25$ (s, $54 \mathrm{H})$. Other peaks were observed at $\delta 2.30(\mathrm{t}$, $J=7.50 \mathrm{~Hz}, 2 \mathrm{H}$ ) which was attributed to a $\mathrm{CH}_{2}$ group $\alpha$ to a carbonyl carbon and at $\delta$ $4.01(\mathrm{~m}, 1 \mathrm{H})$ which was due to a $-\mathrm{CHOH}$ proton. The ${ }^{1} \mathrm{H}-\mathrm{NMR}$ spectrum of $\mathbf{8}$ also exhibited absorptions for three $\mathrm{CH}_{2}-\mathrm{O}$ groups, one of which at $\delta 4.16$ is an ABX system. The other two oxymethylene groups resonated at the same position $\delta[3.46(\mathrm{~m}, 4 \mathrm{H})]$. The ${ }^{13} \mathrm{C}$ NMR spectrum of $\mathbf{8}$ showed a peak due to a carbonyl carbon at $\delta 173.95$ and three peaks for the three $\mathrm{CH}_{2}-\mathrm{O}$ carbons at $\delta 65.40,71.39$ and 71.76. It also revealed the presence of a $\mathrm{CH}-\mathrm{O}$ group at $\delta$ 68.87. Other signals included a $\mathrm{CH}_{3}$ carbon at $\delta 14.10$ and the long chain saturated carbon resonances, all of which are in agreement with structure $\mathbf{8}$. The MS of 8 gave an $[\mathrm{M}+1]^{+}$peak at $\mathrm{m} / z$ 583, which corresponds to the formula $\mathrm{C}_{37} \mathrm{H}_{74} \mathrm{O}_{4}$. The peak at $\mathrm{m} / \mathrm{z} 565$ was attributed to an $[\mathrm{M}$ $\left.\mathrm{H}_{2} \mathrm{O}\right]^{+}$fragment ion. The fragmentation pattern of $\mathbf{8}$ follows the expected fragmentation of alkyl glycerol lipids (Mangold, 1983). Thus the MS exhibited a fragment ion at $\mathrm{m} / \mathrm{z} 239$ which is due to a 
hexadecyl ion, and at $\mathrm{m} / \mathrm{z} 255$ and 327 which correspond to the fragment ions [Ohexadecyl $]$ and $\left[\mathrm{M}^{+}-\right.$(O-hexadecyl) respectively. Other peaks were observed at $\mathrm{m} / \mathrm{z} 299$ and $\mathrm{m} / \mathrm{z} 283$ and these were attributed to fragment ions $\left[\mathrm{M}^{+}-\right.$(octadecyl +30 mass unit)] and [octadecyl + 30 mass unit] respectively.

\section{1-O-octadecyl-2,3-O-dihexadecanoyl-sn- glycerol (7)}

Compound 7 was isolated as white powder. The IR spectrum of 7 differed from that of $\mathbf{6}$ and $\mathbf{8}$, as it did not show a band at $3450 \mathrm{~cm}^{-1}$ due to a hydroxyl group. The spectrum exhibited an absorption at $1727 \mathrm{~cm}^{-1}$ as 8 and at 1467 and $1230 \mathrm{~cm}^{-1}$ as in both 6 and 8. Thus compound $\mathbf{7}$ does not possess a hydroxyl group as it is the case for the other two ether glycols (6 and 8). The signals at 1727 and $1230 \mathrm{~cm}-\mathrm{I}$ in 7 were attributed to the carbonyl and ether groups respectively. The ${ }^{1} \mathrm{H}-\mathrm{NMR}$ spectrum of $\mathbf{7}$ exhibited a signal at $\delta$ 5.20 due to a $\mathrm{CH}-\mathrm{O}$ proton which on irradiation was shown to be coupling with both protons at $\delta 4.35$ and $4.15\left(\mathrm{ABX}, J_{\mathrm{AB}}=\right.$ $\left.11.91 \mathrm{~Hz}, J_{\mathrm{AX}}=6.46 \mathrm{~Hz}, J_{\mathrm{BX}}=3.69 \mathrm{~Hz}, 2 \mathrm{H}\right)$ and at $\delta 3.50(\mathrm{ABX}, 2 \mathrm{H})$, this being an indication of a glycerol oxygenation pattern (Costantino et al., 1993). Other peaks appeared at $\delta 3.40(\mathrm{~m}, 4 \mathrm{H})$ and $2.30(\mathrm{~m}, 4 \mathrm{H})$ which were due to two $\mathrm{CH}_{2}-\mathrm{O}$ and two $\mathrm{CH}_{2}$ groups which are adjacent to a carbonyl carbon respectively. The ${ }^{1} \mathrm{H}-\mathrm{NMR}$ signal at $\delta$ $0.88(\mathrm{t}, J=6.49 \mathrm{~Hz}, 9 \mathrm{H})$ indicated the presence of three terminal methyl groups. The absorption at $\delta 1.25$ (br s, 76H) is due to 38 $\mathrm{CH}_{2}$ groups in alkyl chains. The ${ }^{13} \mathrm{C}-\mathrm{NMR}$ spectrum of 7 indicated the presence of two ester carbonyl carbon absorptions at $\delta 173.13$ and 173.44. It also showed signals at $\delta 62.72$, 68.94 and 71.75 due to three oxymethylene carbons and at $\delta 70.06$ due to an oxymethine carbon. The appearance of two pairs of resonances at $\delta 34.36,34.16$ and 26.04, 24.94 suggested the presence of two alkylacyl groups in the molecule. The remaining resonances in the spectrum were due to $\mathrm{CH}_{3}$ carbons and other $\mathrm{CH}_{2}$ carbons. The MS fragmentation pattern of 7 obeyed the expected fragmentation pattern of $1-O$-alkyl2,3-diacylglycerols (Mangold, 1983). Thus it showed the presence of an octadecyl group at $\mathrm{m} / \mathrm{z} 253$; a peak at $\mathrm{m} / \mathrm{z} 537$ which was assigned to an $\left[\mathrm{M}^{+}\right.$- (octadecyl +30 mass units)] fragment ion and at $m / z 239$ which indicated the presence of a hexadecyl group. The fragment ion at $\mathrm{m} / \mathrm{z}, 565$ is formed after the elimination of 255 mass units $\left[\mathrm{CH}_{3}\left(\mathrm{CH}_{2}\right)_{14} \mathrm{COO}\right]$ from the molecular ion.

\section{Conclusion}

Three ether glycerols were obtained from all studied Lobophytum and the Sinularia species. Since these compounds were obtained from the most polar fractions of the coral extracts, they may not occur in the organisms as such but probably they are hydrolysis products of glycidic phospholipids which are found in most animals. The hydrolysis of the phospholipids might have taken place during the isolation processes. Phospholipids possess a variety of biological potencies in living organisms. Therefore there might be a need to test these compounds for their biological activities once the soft coral phospholipids are obtained in their unhydrolysed state. All three Lobophytum species have been shown to consist of the mixtures of common $\Delta^{5}$-marine sterols (Kerr and Baker, 1991). Furthermore a new epoxysterol, 3 3 -acetoxy-20,22-epoxy-24norcholestane, was also obtained from $L$. rotundum. The epoxide system in the new sterol is expected to undergo a variety of biochemical transformations, forming sterols which have various modifications in the side chain. Therefore, this compound might be one of the biogenetic precursors of the side chain alkylated sterols, which were obtained from the same soft coral as the new sterol. 


\section{ACKNOWLEDGEMENTS}

This investigation received financial support from Netherlands Universities for international Cooperation (NUFFIC) and the UNICEF/UNDP/WORLD BANK/WHO Special Programme for Research and Training in Tropical Diseases (TDR).

\section{REFERENCES}

Blunt JW, Stothers JB. 1977. ${ }^{13} \mathrm{C}$ NMR spectra of steroids - a survey and commentary. Org. Mag. Res., 9: 439-464.

Blunt JW, Copp, BR, Hu WP, Munro MHG, Northcote PT, Prinsep MR. 2009. Marine natural products. Nat. Prod. Rep., 26: 170-244.

Costantino V, Fattorusso E, Mangoni A, Aknin M, Fall A, Samb A, Miralles J. 1993. An unusual ether glycolipid from the Senegalese sponge Trikentrion loeve Carter. Tetrahedron, 49: 2711-2716.

Haefner B. 2003. Drugs from the deep: Marine natural products as drug candidates. Drug Discov. Today, 8: 536544.

Hat BT, Kokke WCMC, Proudfoot JR, Djerassi C, Thompson J. 1985. Minor and trace sterols in marine-invertebrates 53: Further novel marine sterols resulting from triple and quadruple biomethylation of the cholesterol side-chain. Steroids, 45: 263-276.

Kerr RG, Baker BJ. 1991. Marine sterols. Nat. Prod. Rep., 8: 465 - 497.

Kijjoa A, Sawangwong P. 2004. Drugs and cosmetics from the sea. Mar. Drugs, 2: 73-82.

Kingston DGI, Rao MM, Spittler TD, Pettersen RC, Cullen DL. 1975. Sesquiterpenes from Flourensia-cernua. Phytochemistry, 14: 2033-2037.
Kobayashi M, Hayashi T Hayashi K, Tanabe M, Nakagawa T, Mitsuhashi H. 1983. Marine sterols XI. Polyhydroxysterols of the soft coral Sarcophyton glaucum: isolation \& synth. of $5 \alpha$-cholestane1 $\beta, 3 \beta, 5,6 \beta$-tetrol. Chem. Pharm. Bull., 31: $1848-1855$.

Mangold HK. 1983. Ether lipids, Biochemical and Biomedical Aspects. Academic press: New York.

Massey IJ, Djerassi C. 1979. Mass spectrometry in structural and stereochemical problems 252: Structural and stereochemical applications of mass spectrometry in the marine sterol field. Synthesis and electron impact induced mass spectral fragmentation of DELTA 24- and DELTA 24(28)-3 beta-hydroxyDELTA 5-sterols. J. Org. Chem., 44: $2448-2456$.

Newman DJ, Cragg GM. 2004. Marine natural products and related compounds in clinical and advanced preclinical trials. $J$. Nat. Prod., 67: 1216-1238.

Said SA. 2005. An Antimalarial cembranolide from Tanzania soft corals, Lobophytum crassum (von Marenzeller 1886) and $L$. rotundum (Tixier-Durivault 1957). Western Indian Ocean J. Mar. Sci., 4: 9598.

Sarma NS, Krishna MSR, Rao SR. 2005. sterol ring system oxidation pattern in marine sponges. Mar. Drugs, 3:84-111.

Zurcher RF. 1963. Protonen resonanz spektroskopie und steroidstruktur 2 die lage der c-18-und c-19-methylsignale in abhangigkeit von den substituenten am steroidgerus. Helv. Chim. Acta, 46: 20542097. 